\title{
In vitro fermentation profiles of palm kernel meal (PKM)-based diet supplemented with xylanase or cellulase using caecal digesta of broiler chickens as inoculums
}

\author{
Sharmila Ahmad ${ }^{1}$, Azhar K. ${ }^{1}$, Hezmee M. Noor ${ }^{2}$, Anjas A. Samsudin ${ }^{1,3}$ \\ ${ }^{1}$ Department of Animal Science, Faculty of Agriculture, Universiti Putra Malaysia, 43400 Serdang, Selangor, \\ Malaysia. \\ ${ }^{2}$ Department of Pre-clinical Science, Faculty of Veterinary Medicine, Universiti Putra Malaysia, 43400 \\ Serdang, Selangor, Malaysia. \\ ${ }^{3}$ Institute of Tropical Agriculture, Universiti Putra Malaysia, 43400 Serdang, Selangor, Malaysia.
}

\begin{abstract}
In vitro fermentation profiles of palm kernel meal-based diet supplemented with or without xylanase and cellulase were investigated using broiler chickens caecal digesta as inoculum. Caecal digesta from 10 six week old male Cobb 500 broilers was diluted with pre-warmed anaerobic, sterile saline $(9 \mathrm{~g} / \mathrm{L} \mathrm{NaCl})$ in a ratio of 1:5, and was used as inoculum. The PKM-based diet together with semi-defined medium and caecal inoculum was incubated in $100 \mathrm{ml}$ glass syringe for 72 hours at $39 \pm 5{ }^{\circ} \mathrm{C}$. In vitro fermentation kinetics was determined through the in vitro cumulative gas production technique. End products such as ammonia, VFAs, and in vitro dry matter degradability were also quantified. The in vitro study of PKM-based diet supplemented with or without xylanase did not show any different effect on the gas production rate. However, the amount of butyrate production was increased when enzyme was supplemented. Both xylanase and cellulase supplementation in PKM diet had significantly improved $(P<0.05)$ the in vitro dry matter degradability of the PKM compared to unsupplemented PKM diet, which more prominent result shown by xylanase supplementation.
\end{abstract}

Keywords: Xylanase, cellulase and, palm-kernel meal

\section{Introduction}

The plant cell wall constitutes predominantly of dietary fibers together with non-starch polysaccharides (NSPs) and non-carbohydrate components [1]. Simple stomach animal such as poultry contain low level of digestive enzymic activities that are capable of hydrolyzing NSPs component. Therefore, the digestion of these substances is commonly achieved by chemical digestion in crop, physical digestion in the gizzard and mostly through the microbial degradation by bacteria in the caecum [2]. Undigested carbohydrates such as NSPs are fermented in the caeca of poultry into volatile fatty acids (VFAs) and gases [3]. There are few factors affecting the fermentation of dietary fibers including the type and amount of dietary fibers, age of the birds, the caeca development [4] and feed additives [5]. The possible fermentability of feed substrate as well as the effect of feed additives such as enzymes [6] and antibiotics [7] within the target animal can be tested through the in vitro fermentation before added to the diet [8]; [9]. The measurement of gas production has been an important means in the assessment of feed digestibility by microorganisms [10]. The production of gas is considers as end product of microbial fermentation of carbohydrates and it can be determined through a simple and reproducible in vitro technique that determines the potential effect of diet, antimicrobial compounds, feed additives or supplements such as exogenous enzymes on gut microflora [9]. In vitro fermentation technique is a cheaper and faster mean for the purpose of feed evaluation compared to in vivo methods. The in vitro fermentation technique provides a relationship between degradation of feed and fermentative gas production that evaluates the nutritional parameters of feedstuffs. It can be run in a large batch of samples simultaneously at low cost. It also has the ability to measure fermentation kinetics of soluble as well insoluble fraction of food, and the ability to easily make relative comparison among different feedstuffs [11]. The degree of fermentation is usually measured in term of NSPs degradation, VFAs or gas production, or dry matter/organic matter disappearances [11]. For the past 10 years, in vitro study on various classes of monogastric animal including poultry such as broilers [12]; [13], laying hens [14], pigs [15] and equine [16] using either caecal or faecal inocula has become gradually more popular. The effect of the anti-nutritive properties of NSPs on poultry performance and digestibility [17] and intestinal morphology [18] are well documented; however the fermentation characteristics of these components by caecal microorganism [8] are rather limited. Therefore, the present study was conducted to determine the fermentation characteristics of PKM-based diet supplemented with or without xylanase or cellulase using in vitro gas production technique. 
2.1. Semi-defined medium preparation

\section{Materials and Methods}

\subsubsection{Media}

The basal medium was prepared and modified according to [19]. The medium was prepared by mixing $38 \mathrm{ml}$ basal solution, $0.5 \mathrm{ml}$ vitamin/phosphate buffer solution, $2 \mathrm{ml}$ of bicarbonate buffer, and $1 \mathrm{ml}$ of reducing agent. A stream of $\mathrm{CO}_{2}$ flowed in the solution.

\subsection{Broiler chickens caecal preparation}

A group of six week old male Cobb 500 broiler chickens, which had received commercial broiler diet, were obtained from the Poultry Unit at the Department of Animal Science, Universiti Putra Malaysia (UPM). Ten chickens were humanely slaughtered. The caecal digesta were aseptically removed from broilers caeca into a pre-warmed flask flushed with $\mathrm{CO}_{2}$. The caecal digesta collected were immediately transferred to laboratory for the inoculum preparation. The caecal material was weighed and amount of pre-warmed $\left(39^{\circ} \mathrm{C}\right)$, anaerobic, sterile saline $(9 \mathrm{~g} / 1 \mathrm{NaCl})$ was added in a ratio of 1:5. The diluted material was homogenized and strained through double layer of cheesecloth with continually flushed with $\mathrm{CO}_{2}$. The inoculum was added $2.5 \mathrm{ml}$ for each glass syringe.

\subsection{Method of incubation}

The fermentation procedure was carried by the method proposed by [20] with a modification. Approximately $0.25 \mathrm{~g}$ of PKM-based feed sample with or without xylanase and cellulase was put in the glass syringe, followed by basal media together with inoculum. The dry matter (DM) and ash were also measured for all substrates. The fermentation was carried out for $72 \mathrm{~h}$. Following fermentation supernatants were removed from residual substrate by vacuum filtration through pre-weighed sintered glass filter crucibles and rinsed with hot distilled water, and dried at $105^{\circ} \mathrm{C}$ for $24 \mathrm{~h}$. Once the weight recorded, crucibles were placed in a muffle furnace at $550^{\circ} \mathrm{C}$ for ash determination.

\subsection{VFA and ammonia analysis}

After $72 \mathrm{~h}$ incubation, $\mathrm{pH}$ was measured and samples for VFAs and ammonia analysis taken from every glass syringe. Samples for VFAs analysis $(10 \mathrm{ml})$ were added to falcon tube containing $0.5 \mathrm{ml}$ phosphoric acid $(85 \%)$ and frozen at $-20^{\circ} \mathrm{C}$ until analysis. Additional bottles samples $(5 \mathrm{ml})$ were added to falcon tube containing $5 \mathrm{ml}$ of $10 \%$ trichloroacetic acid and were frozen until analysis for ammonia.

\subsubsection{VFAs quantification}

The VFAs were measured following the procedure outlined by [21]. Approximately, $1.5 \mathrm{~g}$ of thawed digesta was diluted with distilled water $(1: 1 \mathrm{wt} / \mathrm{vol})$ in a screw-capped tube. After homogenization and centrifugation, $1 \mathrm{ml}$ of clear supernatant was transferred into ampula, and $0.2 \mathrm{ml}$ metaphosphoric acid solution will be then added. The sample again was homogenize and was placed in ice bath for at least 30 min to allow the protein settle completely. Finally, samples were centrifuged (10 min at 10,844 x g), and the supernatant was analyzed with gas chromatography (Agilent 69890N Series Gas Chromatography System from Agilent Technologies, USA) equipped with a flame ionization detector.

\subsubsection{Ammonia quantification}

The ammonia analysis was measured following the procedure outlined by [22] with a slight modification. Approximately, $5 \mathrm{ml}$ of sample, and $0.2 \mathrm{ml}$ phenol solution was added and swirled. In sequence $0.2 \mathrm{ml}$ of Nitroprusside and $0.5 \mathrm{ml}$ of oxidizing agent were added, swirled and allowed to stand for $1 \mathrm{~h}$. The ammonia was determined using spectrophotometer at absorbance 640nm. The regression equation form blank and standard was determined to estimate ammonia nitrogen in sample.

\subsection{Statistical analysis}

Ammonia, VFAs production, the rate of gas production and IVDMD were subjected to General Linear Model (GLM) procedures of SAS ${ }^{\circledR} 9.0$ (SAS Institute) according to the following general model:

$Y_{i j}=\mu+\alpha_{i}+\delta_{i j}$

Where $Y_{i j}$ is the observed dependent variable; $\mu$ is the overall mean; $\alpha_{i}$ is the effect of enzyme; and $\delta_{i j}$ is the random error. 


\section{Result}

\subsection{Effect of in vitro fermentation on $\mathrm{pH}$, ammonia, VFAs and gas production}

The effect of in vitro fermentation on $\mathrm{pH}$, ammonia $\left(\mathrm{NH}_{3}\right)$ and VFAs production of different feed was shown in Table 1.

\subsubsection{VFA and ammonia production}

The in vitro fermentation of the present study found that acetate production from the fermentation of PKM-based diet for starter diet was significantly higher $(\mathrm{P}<0.01)$ compared to the others. Numerically, the propionate and butyrate production from the fermentation of starter feed ration supplemented with xylanase (T2) were recorded to be the highest. However, no iso-butyrate was detected from the fermentation of all feed ration incubated for $72 \mathrm{~h}$. The ammonia production of in vitro fermentation for all feed ration was also not significantly different $(\mathrm{P}>0.05)$.

Table 1: The in vitro $\mathrm{pH}$, ammonia and VFAs production of PKM supplemented with or without xylanase and cellulase (Mean $\pm \mathrm{SE})$

\begin{tabular}{|c|c|c|c|c|c|c|c|c|}
\hline \multirow[t]{2}{*}{ Substrate } & \multirow{2}{*}{\multicolumn{2}{|c|}{$\begin{array}{c}\text { ammonia } \\
\text { ppm }\end{array}$}} & \multicolumn{6}{|c|}{ VFAs mMol/ml) } \\
\hline & & & Acetate & Propionate & Iso-butyrate & Butyrate & $\begin{array}{c}\text { Iso- } \\
\text { valerate }\end{array}$ & Valerate \\
\hline \multicolumn{9}{|l|}{$\underline{\text { Starter }}$} \\
\hline Control & $6.8 \pm 0.3^{\mathrm{a}}$ & $0.3 \pm 0.19^{b}$ & $298.7 \pm 23.5^{\mathrm{a}}$ & $55.5 \pm 14.8^{\mathrm{a}}$ & - & $35.7 \pm 5.9^{\mathrm{a}}$ & - & - \\
\hline Xylanase & $6.9 \pm 0.3^{\mathrm{a}}$ & $0.4 \pm 0.02^{\mathrm{a}}$ & $89.3 \pm 12.2^{b}$ & $64.3 \pm 15.8^{\mathrm{a}}$ & - & $51.5 \pm 17.7^{\mathrm{a}}$ & - & - \\
\hline Cellulase & $6.8 \pm 0.3^{\mathrm{a}}$ & $0.4 \pm 0.02^{\mathrm{a}}$ & $76.9 \pm 11.9^{\mathrm{bc}}$ & $41.2 \pm 3.2^{\mathrm{a}}$ & - & $40.8 \pm 1.8^{\mathrm{a}}$ & $5.8 \pm 0.8^{a}$ & $5.8 \pm 0.4^{\mathrm{a}}$ \\
\hline \multicolumn{9}{|l|}{ Finisher } \\
\hline Control & $6.8 \pm 0.0^{\mathrm{a}}$ & $0.4 \pm 0.02^{\mathrm{a}}$ & $113.4 \pm 13.3^{b}$ & $43.7 \pm 9.4^{\mathrm{a}}$ & - & $35.7 \pm 5.9^{\mathrm{a}}$ & - & - \\
\hline Xylanase & $6.8 \pm 0.3^{\mathrm{a}}$ & $0.4 \pm 0.02^{\mathrm{a}}$ & $98.8 \pm 12.2^{\mathrm{b}}$ & $41.3 \pm 3.8^{\mathrm{a}}$ & - & $39.1 \pm 2.4^{\mathrm{a}}$ & $4.8 \pm 0.0^{\mathrm{a}}$ & $4.8 \pm 0.0^{\mathrm{a}}$ \\
\hline Cellulase & $6.8 \pm 0.0^{\mathrm{a}}$ & $0.4 \pm 0.02^{\mathrm{a}}$ & $37.3 \pm 5.3^{\mathrm{c}}$ & $38.8 \pm 8.6^{\mathrm{a}}$ & - & $39.0 \pm 8.8^{\mathrm{a}}$ & - & - \\
\hline $\mathbf{P}$ & NS & NS & $* *$ & NS & - & NS & NS & NS \\
\hline
\end{tabular}

NS; Not significant

$*$ Significantly different at $5 \%$ level $(\mathrm{P}<0.05)$, **significantly different at $1 \%$ level $(\mathrm{P}<0.01)$

a, b, and c: Means with different letter within a column differed significantly for $\mathrm{pH}$, ammonia and VFAs

\subsubsection{Gas production profiles}

The gas production profiles for six different feed rations incubated for $72 \mathrm{~h}$ are presented in Fig. 1. The gas production of the six feed rations was observed to be similar in trend. The total gas production (ml) was highest in the finisher PKM-based diet supplemented with cellulase and lowest in starter PKM-based diet without any enzyme addition.

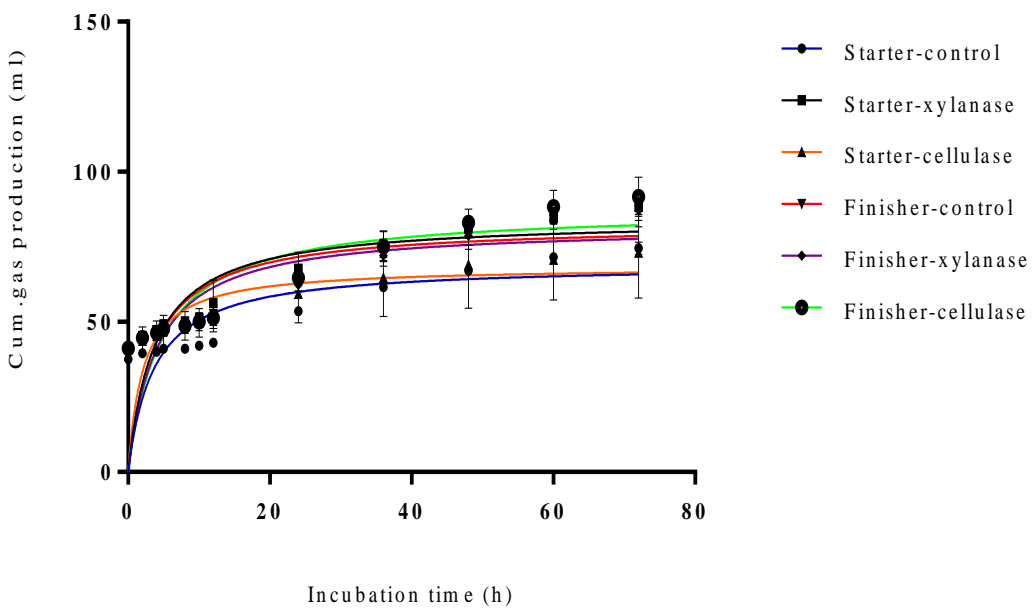

Figure 1: Gas production profiles from fermentation of the PKM-based diet for starter and finisher supplemented or non-supplemented with xylanase or cellulase means \pm SE of four replicate for each feed sample. 
In vitro fermentation profiles of palm kernel meal (PKM)-based diet supplemented with...

\subsubsection{Fermentation kinetics}

Table 2 shows the gas production kinetic parameters and in vitro dry matter degradability (IVMD) after $72 \mathrm{~h}$ of incubation of PKM-based diet for starter and finisher supplemented with or without xylanase and cellulase supplementation. The rate of gas production (Table 2) was found to be not significantly different $(\mathrm{P}>0.05)$ between enzyme supplemented and unsupplemented PKM ration for both starter and finisher. However, the rate of gas production of xylanase and cellulase supplemented for starter PKM ration was higher compared to non-supplemented group and vice versa for finisher PKM ration. The gas production from soluble and insoluble fraction of feed substrate noted by ' $\mathbf{a}$ ' and ' $\mathbf{b}$ ' respectively was also not significantly different $(\mathrm{P}>0.05)$ between all feed ration. The gas production from insoluble fraction $(\mathbf{b})$ of feed substrate for all feed ration were higher compared to the soluble fraction (a) of feed substrate. Supplementation of xylanase and cellulase in PKM-based diet improved the gas production from the soluble fraction of the feed compared to control. However this result is not similar in finisher feed ration supplemented with xylanase. The IVMD of all groups of the feed ration were highly significant different $(\mathrm{P}<0.05)$. Xylanase and cellulase supplementation increase the IVMD of PKM-based diet, in which more prominent result obtained by xylanase supplementation.

Table 2: The fermentation kinetics of PKM diet supplemented with or without xylanase or cellulase incubated for 72 hours

\begin{tabular}{|c|c|c|c|c|c|}
\hline & Rate of gas production $\mathrm{c}^{(\mathrm{h}-1)}$ & & & & IVDMD \\
\hline Substrate & Mean \pm SE & $\overline{\mathbf{a}}$ & b & RSD & Mean \\
\hline \multicolumn{6}{|l|}{$\underline{\text { Starter }}$} \\
\hline Control & $0.01 \pm 0.00^{\mathrm{a}}$ & $36.62^{\mathrm{a}}$ & $62.29^{\mathrm{a}}$ & 1.41 & $7.24 \pm 0.82^{b}$ \\
\hline Xylanase & $0.02 \pm 0.00^{\mathrm{a}}$ & $40.57^{\mathrm{a}}$ & $59.57^{\mathrm{a}}$ & 1.99 & $11.09 \pm 0.16^{\mathrm{b}}$ \\
\hline Cellulase & $0.02 \pm 0.00^{\mathrm{a}}$ & $40.25^{\mathrm{a}}$ & $53.94^{\mathrm{a}}$ & 1.61 & $8.08 \pm 0.89^{\mathrm{b}}$ \\
\hline \multicolumn{6}{|l|}{$\underline{\text { Finisher }}$} \\
\hline Control & $0.02 \pm 0.00^{\mathrm{a}}$ & $40.54^{\mathrm{a}}$ & $120.47^{\mathrm{a}}$ & 1.94 & $7.49 \pm 0.72^{\mathrm{b}}$ \\
\hline Xylanase & $0.01 \pm 0.00^{\mathrm{a}}$ & $39.96^{\mathrm{a}}$ & $64.73^{\mathrm{a}}$ & 1.48 & $17.59 \pm 2.83^{\mathrm{a}}$ \\
\hline Cellulase & $0.01 \pm 0.00^{\mathrm{a}}$ & $78.64^{\mathrm{a}}$ & $78.64^{\mathrm{a}}$ & 1.72 & $7.79 \pm 0.79^{\mathrm{b}}$ \\
\hline $\mathbf{P}$ & NS & NS & NS & & $* *$ \\
\hline
\end{tabular}

a: Soluble fraction; b: Insoluble fraction

IVDMD; In vitro dry matter degradability

NS; Not significant

$*$ Significantly different at $5 \%$ level $(\mathrm{P}<0.05)$, **significantly different at $1 \%$ level $(\mathrm{P}<0.01)$

a, b, and c: Means with different letter within a column differed significantly

\section{Discussion}

\subsection{In vitro, $\mathrm{pH}$, ammonia and VFAs production}

Some dietary fiber such as NSPs component are not hydrolyzed in the upper part of intestinal tract of broiler chickens but are fermented in caeca by anaerobic microflora, which produced VFAs that provide energy to the host animal and inhibit the growth of pathogenic bacteria [4]. VFAs such as acetate, propionate and butyrate have nutritional value to animal because they provide energy for hen, and [23] estimated that 30 to $40 \%$ of the maintenance energy for monogastric is derived from the microbial fermentation. The supplementation of diets with exogenous enzyme such as carbohydrases [24]; [25] might influence VFAs concentration by releasing nutrient entrapped in the plant cell walls polysaccharides accessible for hindgut fermentation [5]. In vitro study conducted by [26] and [27] demonstrated that acetate production was highest followed by propionate and butyrate whereas iso-butyrate and iso-valerate production were detected in very minimal amount. Generally, in ruminants, rapidly fermentable substrates have a relatively higher propionate production, whereas more slowly fermentable and cellulose rich substrates have acetic acid directed fermentation [13]. This statement was in agreement with the present findings, where the highest amount of acetate was observed in the enzyme nonsupplemented group due to high cellulosic content in the PKM-based diet. On the other hands, the propionate and butyrate production was found to be higher in the fermentation of PKM-based diet supplemented with xylanase compared to other feed rations. Xylanase supplemented PKM-based diet may influence the degradation of NSPs particularly xylan to simpler form, xylose sugar which can be rapidly fermented by caecal microbial [7]; [28]. The iso-valerate was produced in a trace amount in xylanase and cellulase supplemented groups, whereas no iso-butyrate and valerate production was found in all feed ration. The finding of the present study was in agreement with a data recorded by [29] and [27] where the fermentation of high fiber diets incubated with caecal inocula from broiler chickens and equine recorded with higher acetate level followed by 
In vitro fermentation profiles of palm kernel meal (PKM)-based diet supplemented with...

propionate and butyrate whereas iso-butyrate and iso-valerate production were recorded in trace amount. Overall, the results is actually difficult to explained because the VFA s produced through the caecal fermentation can be quite variable and it also may be influenced by non-carbohydrate compounds such as protein [1], lignin, and fatty acids, [11]. Beside the degradation of high fiber feed, caeca also play an important role in the hydrolyzation of nitrogenous compounds such as protein, amino acids to generate ammonia, amines, phenol and branched chain fatty acids [30]. However, the present study observed that ammonia production was not significantly different either PKM was incubated together with xylanase or cellulase.

\subsection{In vitro gas production profile, fermentation kinetics and IVDMD}

Fermentation model differed in cultures with different feed substrates [3] and, there is a close association between microbial fermentation and gas production [31]. The measurement of gas production has been an important means in the determination of feed digestibility by microorganisms [10], as well as the effect of feed additives such as enzymes [6]. The gas was produced from the fermentation of carbohydrates to vfa particularly, acetate and butyrate [32] and is therefore highly associated with apparent digestibility of feeds in vivo [33]. The gas production pattern of PKM-based diets in enzyme supplemented or non-supplemented group tested in the in vitro fermentation study was found to be similar in trend. The gas was rapidly produced in the early stage of incubation until it reaches a state where the gas production starts to slow and reach plateau. The high amount of gas produced in the early stage was due to the availability of the feed substrate that was used by microorganism to multiply and grow. After the rate of fermentation has reached maximum level, the gas production gradually decreased until it stops. This is due to depletion of feed substrate or insoluble components associated with chemical or structural barrier such as crystallinity of cellulose and the toxic action of cell wall phenolics can impose the digestion [34]; [35]; [36]. In the present study, higher cumulative gas was produced from the fermentation of finisher PKM-based diet in enzyme non-supplemented group. This is due to the higher amounts of insoluble fractional substrate (noted as $\mathbf{b}$ in Table 6) available to be further fermented. Non-soluble feed substrates will be more slowly fermented and are likely to be fermented later part of the intestinal tract such as in caeca [37]. Feed substrates are partially solubilized upon incubation, and the soluble components are fermented rapidly until a gradual shift occurs towards the fermentation of the insoluble substrates. This process requires the substrate to be hydrated and colonized by microorganism before they can be fermented [38]; [36]. The fermentation kinetics of feed substrates may also provide an understanding of where the product is likely to be fermented and this information can be further used to formulate diets that encourage fermentation in specific areas of intestinal tract of broiler chickens [37]. Numerically, the rate of gas production in the present study was found to be higher from the fermentation of starter PKM-based diet supplemented with xylanase and cellulase compared to non-supplemented group. Addition of xylanase and cellulase enzyme in PKM-based diet improved the availability of soluble fractional substrates for the fermentation, compared to insoluble fractional substrates. Inclusion of xylanase and cellulase also improved the IVDMD of PKM-based diet in broiler chicken's caeca. [39] reported that NSPs enzymes enhanced the nutrient delivery to the host by providing fermentable oligosaccharides from NSPs to the caecal microbiota which improved the digestibility of feeds and finally affecting the fermentation profiles in the broiler chickens caeca.

\section{Conclusion}

The gas production rate of PKM-based feed supplemented with xylanase and cellulase enzyme was found not much different from the non-supplemented group. The butyrate production of PKM-based diet in enzyme supplemented group was recorded higher than the other group. The butyrate produced can be utilized directly by caecal epithelium, which derives approximately 60-70\% of its energy from products of bacterial fermentation. Both xylanase and cellulase supplementation in PKM-based diet improved IVDMD. Enzyme supplementation enhanced the nutrient delivery to the host by providing fermentable oligosaccharides from NSPs to the caecal microbiota which improved the digestibility of feeds and finally affecting the fermentation profiles in the broiler chickens caeca [39].

\section{References}

[1]. K.E. Bach Knudsen, The nutritional significance of "dietary fiber" analysis, Animal Feed and Science Technology, (90), 2001, 3-20.

[2]. M. Choct, R.J. Hughes, and M.R. Bedford, Effects of a xylanase on individual bird variation, starch digestion throughout the intestine, ileal and ceacal volatile fatty acid production in chickens fed wheat, British Poultry Science, 40, (1999), 419-422.

[3]. M. Marounek, O. Suchorska, and O. Savka, Effect of substrate and feed antibiotics on in vitro production of volatile fatty acids in caecal contents of chickens, Animal Feed and Science and Technology, 80, (1999), 223-230.

[4]. D. Józefiak, A. Rutkowski, and S.A. Martin, Carbohydrate fermentation in the avian ceaca, Animal Feed and Science Technology, 113, ( 2004), 1-15.

[5]. A. Chesson, Feed enzyme. Animal Feed and Science and Technology, 45, (1993), 65-79.

[6]. J. McLean, I. Nevison, G. Bertin, and T. Acamovic, The feasibility of using nutritional modifications to replace drugs in poultry feeds, Journal of Applied Poultry Research, 11(4) (2004), 437-452.

[7]. M.R. Bedford, Exogenous enzymes in monogastric nutrition- their current value and future benefits, Animal Feed and Science Technology, 86, (2000), 1-13. 
In vitro fermentation profiles of palm kernel meal (PKM)-based diet supplemented with...

[8]. Y. Lan, B.A. Williams, S. Tamingga, H. Boer, A. Akkermans, G. Erdi, and M.W.A. Verstegen, In vitro fermentation kinetics of some non-digestible carbohydrates by the caecal microbial community of broilers, Animal feed science and Technology,123-124, (2005), 687-702.

[9]. S. Shanmugavelu, G. Ruzickova, G. Zrustova, and J.D. Brooker, A fermentation assay to evaluate the effectiveness of antimicrobial agents on gut microflora, Journal of Microbiological Methods, 67, (2006), 93-101.

[10]. K. H. Menke, L. Raab, A. Salewski, H. Steingass, D. Fritz, and W. Schneider, The estimation of digestibility and metabolizable energy content of ruminant's feedstuffs from gas production when they are incubated with rumen liquor in vitro, Journal of Agricultural Science in Cambridge, 93, (1979), 217-222.

[11]. L.T. Coles, P.J. Moughan, and A.J. Darragh, In vitro digestion and fermentation methods, including gas production techniques, as applied to nutritive evaluation of foods in the hindgut of humans and other simple-stomached animal, Animal Feed and Science Technology. 123-124, (2005), 421-444.

[12]. A. Meimandipour, M. Shuhaimi, M. Hair-Bejo, K. Azhar, B.M. Kabeir, B. Rasti, and A.M. Yazid, In vitro fermentation of broiler cecal content: the role of lactobacilli and $\mathrm{pH}$ value on the composition of microbiota and end products fermentation, Applied Microbiology, 49, (2009), 415-420.

[13]. F.C. Guo, B.A. Williams, R.P. Kwakkel, and M.W.A. Verstegen, In Vitro Fermentation Characteristics of Two Mushroom Species, and Herb, and Their Polysaccharide Fractions, Using Chicken Caecal Contents as Inoculums, Poultry Science, 82, (2003), 16081615 .

[14]. L.M. Donalson, W.K. Kim, V.I. Chalova, P. Herrera, J.L. McReynolds, V.G. Gotcheva, D. Vidonovič, C.L. Woodward, L.F. Kubena, D.J. Nisbet, and S.C. Ricke, In vitro Fermentation Response of Laying Hen Cecal Bacteria to Combinations of Fructooligosaccharides Prebiotics with Alfalfa or a Layer Ration, Poultry Science, 87, (2008) ,1263-1275.

[15]. F. Ahrens, J. Schön, M. Schmitz, A discontinuous in vitro technique for measuring hind gut fermentation in pigs, in M.W.A. Verstegen, J. Huisman, L.A. den Hortog, (Ed). Digestive Physiology in Pigs. The Netherlands: EAAP Publication no.54. Pudoc, Wageningen, 1991), 226-230.

[16]. J.M. Lattimer, S.R. Cooper, D.W. Freeman, and D.L. Lalman, Effect of Aspergillus yeast culture on in vitro fermentation of highconcentrate or high fiber diet using equine fecal inoculums in a Daisy ${ }^{11}$ incubator, Journal Animal Science, 85, (2007), $2848-2491$.

[17]. H. Q. Zhang, H. Ye, W. C. Wang, Z.M. Dong, J. Lin, and L. Yang, Effect of dietary fiber on growth performance, enzyme activities, microflora and digesta physiochemical characteristics of Lionhead gees, Journal of Agriculture and Environment, 11(3\&4), (2013), 1653-1658.

[18]. L. Stef, G. Dumitrescu, D. Drinceanu, D. Stef, J. Călin, C. Nicole, P. Cosmin, and S. Ioana, Impact of Wheat Non Starch Polysaccharide on the Intestinal Wall and Microflora in Broilers, Animal Science Biotechnology, 43(1), (2010), 111-116.

[19]. S.E. Lowe, M.K. Theodorou, A.P.J. Trinci, R.B. Hespell, Growth of anaerobic rumen fungi on defined and semi-defined media lacking rumen fluid, Journal Genetic and Microbiology, 131, (1985), 2225-2229.

[20]. K.H. Menke, and H. Steingass, Estimation of the energetic feed value obtained from chemical analysis and in vitro gas production using rumen fluid, Animal Resources and Development, 28, (1988), 7-55.

[21]. J.J. Wang, J.D. Garlich, and J.C.H. Shih, Beneficial effects of Versazyme, a Keratinase feed additive, on body weight, feed conversion, and breast yield of broiler chickens, Poultry Science Research, 15, (2005), 544-550.

[22]. T. R. Parson, Y. Maita, and C.A. Laili, Mannual of chemical and biological methods for seawater analysis. New York; Pergamon Press, 1984

[23]. T. Tsukahara, and K. Ushida, Effects of animal or plant protein diets on cecal fermentation in guinea pigs (Cavia porcellus), rat (Rattus norvegicus) and chickens (Gallus gallus domesticus), Comparative Biochemistry and Physiology, 127, (2000), 139-146.

[24]. H. Graham, and D. Pettersson, A note on the effect of beta-glucanase and a multi-enzyme on production in broiler chicks fed a barley-based diet, Sweden Journal of Agricultural Research, 22, (1992), 39-42.

[25]. D. Jamroz, T. Wertelecki, A. Wiliczkiewiz, J. Orda, and J. Shorupinska, Dynamic of yolk Sac resorption and post-hatching development of gastrointestinal tract in chickens, ducks and geese, Journal Animal Physiology and Animal Nutrition, 88(5-6), (2004), 239-250.

[26]. S. Saengkerdsub, W. Kim, R.C. Anderson, D.J. Nisbet, and C. Ricke, Effects of nitrocompounds and feedstuffs on in vitro methane production in chickens cecal contents and rumen fluid, Anaerobe, 12, (2006), 85-92.

[27]. D.K. Dunkley, C.S. Dunkley, N.L. Njongmeta, T.R. Callaway, M.E. Hume, L.F. Kubena, D.J. Nisbet, and S.C. Ricke, Comparison of In Vitro Fermentation and Molecular Microbial Profiles of High Fiber Substrates Incubated with Chicken Cecal Inocula, Poultry Science, (2007), 801-809.

[28]. R.M. Engberg, M.S. Hedemann, S. Steenfeldt, and B.B. Jensen, Influence of Whole Wheat and Xylanase on broiler Performance and Microbial Composition and Activity in the Digestive Tract, Poultry Science, 83, (2004), 925-938.

[29]. A.L. McDaniel, S.A. Martin, J.S. McCann, and A.H. Parks, Effects of Aspergillus oryzae fermentation extract on in vitro equine cecal fermentation, Journal of Animal Science. 71, (1993), 2164-2172.

[30]. J.H. Cummings, and G.T. Macfarlane, Role of intestinal bacteria in nutrient metabolism, Journal of Clinical Nutrition, 16, (1997), 3-11

[31]. G.M. Getachew, M. Blummel, H.P.S. Makkar, and K. Becker, In vitro gas measuring techniques for assessment of nutritional quality of feed. A review, Animal Feed Science and Technology, 72, (1998), 261-281.

[32]. M. Blummel, and E.R. Ørskov, Comparison of in vitro gas production and nylon bag degradability of roughages in predicting feed intake in cattle, Animal Feed Science and Technology, 40, (1993), 109-119.

[33]. H.P.S. Makkar, M. Blummel, K. Becker, Formation of complexes between polyvinyl pyrrolidones of polyethylene glycols and tannins, and their implication in gas production and true digestibility in in vitro techniques, British Journal of Nutrition, 73, (1995), 897-913.

[34]. [M.S. Kerley, G.C. Fahey Jr, J.M. Gould, and E.L. Lannotti, Effects of lignifications, cellulose crystallinity and enzyme accessible space on the digestibility of plant cell wall carbohydrates in the ruminant, Food Microstructure, 7, (1988), 59-65.

[35]. A. Cornu, J.M. Besle, P. Mosoni, and E. Grenet, Lignin-carbohydrate complexes in forages: structure and consequences in the ruminal degradation of cell-wall carbohydrates, Reproduction and Nutrition Development, 34, (1994), 385-398.

[36]. J.C.J. Groot, B.A. Williams, F.M.A. Debersaques, and A. Lantiga, Multiphasic analysis of gas production kinetics for in vitro fermentation of ruminant feeds, Animal Feed and Science Technology, 64, (1996), 77-99.

[37]. B.A. Williams, W.B. Marlou, H. Boer, W.A. Martin, and S. Tamminga, An in vitro batch culture method to assess potential fermentability of feed ingredients for monogastric diets, Animal Feed and Technology, (123-124), (2005), 445-462.

[38]. J. Van Milgen, L.L. Berger, and J. Murphy, An integrated, dynamic model of feed hydration and digestion, and subsequent bacterial mass accumulation in the rumen, British Journal Nutrition, 70, (1993), 471-483. 
In vitro fermentation profiles of palm kernel meal (PKM)-based diet supplemented with...

[39]. M.R. Bedford, and A.J. Cowieson, Exogenous enzymes and their effects on intestinal microbiology, Animal Feed and Science Technology, 173, (2012), 76-85. 